\title{
Selecting a Discrete Multiple Criteria Decision Making Method for Boeing to rank four global market regions
}

\begin{abstract}
Haddad, M. Sanders, D. and Tewkesbury, G.
Abstract-This work describes the creation of a new method to choose a suitable Multi-Criteria Decision Making (MCDM) method for a Boeing strategic decision. The decision involved four global market regions being ranked based on their market attractiveness and competitive strength when risk and uncertainty were anticipated. Following an analysis of MCDM problems and methods, a new organized approach was created to provide a decision maker with a sub-group of suitable MCDM methods. Sensitivity analysis was used to investigate the robustness of the outputs from the various candidate methods. A MCDM method is recommended automatically. The recommended candidate method is the one that provided the most robust output (solution to the problem). Only methods that deal with a discrete set of choices were considered. In the Boeing strategic decision presented in this paper, two MCDM methods were compared and a recommendation was made after calculating the minimum percentage change in performance measures and criteria weights required to change the ranking of any two alternatives. An MCDM method was recommended based on a compromise between the minimum percentage change that was required in the inputs to change the ranking of alternatives. Some propositions are discussed based on general scenarios concerning MCDM problems.
\end{abstract}

Keywords: Strategic, Decisions, Market regions Multiple criteria, Analysis, Robustness, Sensitivity, Decision making, Criteria Weights, Performance.

\section{Introduction}

Airbus posed a threat to the commercial jet aircraft market dominated by Boeing and Boeing wanted to evaluate their market attractiveness and competitive strength.

This paper describes the choice of a suitable MCDM method to use for the Boeing strategic decision. Making a decision involves assessing alternatives and selecting a course of action or choice to achieve an objective or goal. Appropriate decision-making processes can be important in an organization but the available information may be vague and the actual problems can be uncertain. Decision-making is getting more complicated. Problems have large numbers of alternatives and the various criteria often conflict (Razmak \& Aouni, 2015). 
The research work described in this paper investigates the effect of the choice of method for a Boeing strategic decision involving four global market regions being ranked based on their market attractiveness and competitive strength when uncertainty and risk may be present. An automatic system is described that selects a sub-group of MCDM methods. Sensitivity analysis was employed to test the sub-group and a suitable method has been recommended. From that work, some new general propositions have been developed based on a set of generalized potential MCDM scenarios. These are explained.

Since the first flight by Orville and Wilbur Wright, more than a hundred years ago, the air transport industry has grown to be a large sector of the global economy (Barnhart et al, 2003). Airlines developed and maintained cultural and economic links between countries, cultures and people. Airlines generated more than $\$ 300$ billion in revenues in 2002 and were expected to grow at an annual rate of $4 \%-5 \%$ over the next 20 years (Barnhart et al, 2003). In 2003, the airlines carried 1.6 billion passengers, created 28 million direct, indirect and induced jobs worldwide and carried more than $40 \%$ of the value of international trade worldwide Collaborative Forum, 2003).

Boeing is the world's largest aerospace company and leading manufacturer of commercial jetliners and service provider of aftermarket support. As America's biggest manufacturing exporter, the company supports airlines and U.S. and allied government customers in more than 150 countries. Boeing products and tailored services include commercial and military aircraft, satellites, weapons, electronic and defence systems, launch systems, advanced information and communication systems, and performance-based logistics and training.

Mahtani and Garg (2018) stressed the importance of management decisions in identifying key factors with influence on the financial conditions of companies to maintain good growth rate. Pacheco and Fernandes (2017) associated air transport growth to a number of factors including: government measures to liberalise prices, greater flexibility in air freedom, privatising infrastructure and growth in income expressed as Gross Domestic Product (GDP).

Sha et al, (2015) employed the Federal Airline Association (FAA) predictions of market demand to calculate predicted market region growth. They stressed that predicting the market growth even for only one year ahead could be very sensitive to and highly depended on uncertainty. Mahtani and Garg (2018) pointed to the difficulty of accurately predicting market growth regions for more than two years. Pacheco and Fernandes (2017) claimed that decision makers for air transport sector needed to consider the economic factors broadly, to involve factors beyond tourism, regulation and sector infrastructure.

Operations Research (OR) played an important role in helping the airline industry and its infrastructure to maintain good growth rates (Barnhart et al, 2003). Multi-Criteria Decision Making (MCDM) is a field of operational research where alternatives are assessed to select the most suitable alternative to fulfil a desired goal with respect to multiple and often conflicting criteria (Barbosa et al, 2017; Ishizaka \& Siraj, 2018). MCDM can be considered as a systematic process for analysing and choosing between alternatives. It aims to split a 
problem into smaller parts, analysing and assessing each part, then aggregating all parts to select the best feasible alternative from a set of alternatives using a predefined set of criteria.

Boeing wanted to evaluate their market attractiveness and competitive strength in four global markets: United States, Asia, Europe and the Middle East. A set of twenty-four criteria were identified to do that. The factors addressed in this paper considered the changing nature of airline needs and the international business environment. Market attractiveness included political climate, competitive intensity, growth and size. The competitive strength in each of the four regions was assessed based on relative market share, price competition, aircraft quality, and customer knowledge of each type of plane. Data was taken from Expert Choice (2013)

A set of eight main criteria were established: market size, share, growth and competitive intensity, political factors enhancing the market size, price competition, product quality and customer knowledge, for the various sizes of passenger plane.

This paper describes the selection of a suitable MCDM method to use for the Boeing strategic decision. The decision involved four global market regions being ranked based on their market attractiveness and competitive strength in the face of risk and uncertainty. Novel propositions are presented that arose from a study of general decision-making scenarios and MCDM problems. The propositions have been tested on other numerical examples that were available from the authors and results suggested the propositions were true and that they predict suitable MCDM methods. A Boeing strategic decision (Expert Choice, 2013) was considered in this paper and was used to test the propositions.

Researchers have emphasised a need to include uncertainty within their decision-making systems (French, 2003; Stewart, 2005; Durbach \& Stewart, 2011; 2012; Haddad et al, 2019), however in practice, it is rarely actually considered. Haddad and Sanders (2018) said decision-makers understand that the data they are using to solve real world problems is often uncertain. Scholten et al (2015) said the input data is often "illdetermined", and diverse situations could be possible and apply. They said it is the duty of the decision-maker to supply information about the soundness of the decision outcomes, the models used and the methods applied to solve the problem.

Different sorts of real-life problem need different sorts of decision-making methods, and no method is superior to all the other methods. Haddad et al (2019) said that different weighting methods often provide different solutions to a problem.

Making a judgment within a fuzzy, high risk and uncertain environment (where many assumptions may be made and high stakes may be involved) made decision susceptible to being distorted. The use of a more complex scientific decision-making method might improve the solution. Humans can only deal with a 
relatively small number of criteria at any one time (Miller, 1956). To manage complicated multi-criteria problems in an efficient way, decision makers tend to make use of MCDM.

\section{MCDM Methods}

Wang et al (2010) regards MCDM as a branch of Operational Research (OR) that is useful for some complicated problems within risky or uncertain situations. Eyvindson et al (2018) describes them as mathematical methods used to find a best compromise solution based on judgments provided by stakeholders. For two decades, MCDM has been one of the quickest emerging areas within OR. It has been used to sort alternatives into predefined groups, to rank alternatives, to select best fits, and to describe problems (Roy, 1985). MCDM methods can handle conflicting criteria to tackle complex problems in business, engineering, management, science and other applications (Maleki \& Zahir, 2013). Haddad et al (2018a) said that MCDM methods help decision makers to understand their problems and the factors that might influence the problems in an attempt to produce "Good" enough solutions. Razmak and Aouni (2015) stated that MCDM methods could be broadly categorized into Multi-Objective Programming and Multi-Attribute Decision Making.

Durbach and Stewart (2012) claimed that all multi-criteria methods improved decision making. That is achieved by decomposing assessment of the alternatives into a number of possibly conflicting criteria. It can be challenging to test MCDM methods to see how accurate they are because they use different methods and are difficult to compare (Olson et al, 2007). MCDM methods perform more efficiently for particular types of problems (Razmak and Aouni, 2015). MCDM is sequential although a user can go through a number of iterations in an attempt to produce a robust solution. Being able to check on the consistency of the comparisons made could be important.

Human judgment is prone to error and bias, and Comes et al (2013) identified some noticeable biases: Confirmation bias; Anchoring bias; Availability bias. Human behaviour is a source of inconsistency but it is not the only one. Decision makers describe alternatives and criteria on scales with limited sets of numbers so that digitisation errors appear and the measurement scales used for different methods can provide some inconsistency (Haddad et al, 2019).

Decision makers need to appreciate potential uncertainty to improve the decisions they make and reduce risk. Moreover, decision makers' understanding of uncertainty could lower inconsistency rates and lead to more reliable and robust representations of weights and performance measures (Haddad et al, 2019; Norese, 2016). Scholten et al (2015) claimed that uncertainty in criteria weights could be present because of bias, inaccurate quantitative estimates, or because of the use of inexact weights. Under-rating uncertainty can have an adverse effect on long-term planning because the costs of making a wrong decision can be significant.

Roy (2010) stressed on the importance of including the robustness of results in the decision making process. Moreover, Roy claimed that an appropriate solution for a problem could be the solution that took into 
consideration the presence of "vague approximation and zones of ignorance" and prevented undesirable impacts.

Haddad et al (2018b) said there is not a perfect MCDM method. Decision-makers may not be able to provide all the information and different problems will need different algorithms to produce suitable outcomes. Haddad et al (2019) said that problems and criteria weights are often hard to describe as "exact" numbers in real life. They presented examples where criteria values could not be defined as exact numbers and instead, modelled criterion weight uncertainty as fuzzy values and probability functions. They said inaccuracy could be understood more by using Pseudo criteria; introducing indifference and preference thresholds so that inaccuracy might filtered out between them.

Strategic decision making often involve a high degree of risk, uncertainty, major resource implications and long-term consequences (Montiliber \& Franco, 2010). In order for standard MCDM methods to be considered as an effective tool for strategic decision making problems Montiliber and Franco (2010) suggested a number of changes to standard MCDM methods. These changes required the consideration both technical and social aspects of strategic decision making.

Montiliber and Franco (2010) stated different of causes of uncertainties in strategic decision making which were related to the lack of complete knowledge about an organization's external environments and its impact on the performances of potential strategies, lack of understanding which strategic objective and policy values should guide the decision process and uncertainty due to inter-relationship among choice.

Many researchers applied MCDM methods to transportation problems. Mahtani and Garg (2018) applied Fuzzy AHP to highlight the important factors of financial stability for airline companies in India. They analysed factors that were dependent on the internal operations of the company and on the external environment. They mentioned that financial factors were the key parameters that needed to be monitored and tracked regularly for the financial stability of the airlines. Barbosa et al (2017) developed a MCDM model for different transportation methods in Brazil to identify important factors that determined users' opinions of services and enabled their improvements. Their work contributed to the strategic planning and allocation of investments, expanded the transportation sector, and continuously improved the service levels. They also recommended applying sensitivity analysis to identify the important factors that affected the quality of service. Nassereddine and Eskandarib (2017) developed a model for the evaluation of public transportation systems based on the Delphi method, group AHP and PROMETHEE, then they conducted sensitivity analysis to investigate the effect of criteria weights on the outcome of the methods. Their results introduced future improvements of the quality of service,

An element of risk is present in all decision-making. Risk is an uncertain condition or event that could have positive or negative effects on objectives. Internal risks include time, cost and team changes. External risks include change in regulations, market shift, technical issues, and unforeseeable risk. The Project Management 
Institute (2004) say that $90 \%$ of problems might be evaded if better risk management was applied. Decision makers should capture, enhance and exploit positive risk (that is opportunity), and transfer, mitigate and avoid negative risk (threat).

Sensitivity analysis should be performed to validate the feasibility and to check the robustness of MCDM solutions (Saaty \& Ergu, 2015). Saltelli et al (2000) defined sensitivity analysis as the analysis of the effect of uncertainty in the output of a model, affected by uncertainty in its inputs. Haddad et al (2019) suggested that it is best to conduct sensitivity analysis on both the performance measures and the criteria weights. Sun et al (2011) mentioned that robustness is an indicator of the ability of a system to tolerate uncontrollable changes in inputs.

Three types of sensitivity analysis were defined by Wolters and Mareschal (1995) for problems:

- The effect of changes in performance measures of one alternative with respect to a criterion.

- Sensitivity of a ranking to changes in scores of all alternatives depending on certain criterion represented as criterion scores.

- The minimum change in criteria weights required to make an alternative ranked first.

Haddad (2017) identified the following steps to reach a most suitable (best compromise) solution in any multicriteria problem:

- Identify the problem.

- Define goals and targets.

- Define a set of criteria.

- Identify alternatives.

- Select a MCDM method to evaluate the overall score of alternatives with respect to the criteria set.

- Review and evaluate outcomes.

The decision process was iterative and at the end of the process, decisions were reviewed and then validated. Ineffective Failed or unsuitable decisions were reconsidered before starting the decision process again.

Because strategic decisions are often uncertain and ambiguous and can involve a lot of stakeholders with varying preferences, they can be difficult to make (Comes et al, 2013). Grechuk and Zabarankin (2018) modelled the decision making process into 4 stages which included uncertainty. They said that analysts and decision makers have experimental and historical data, which is not sufficient. Data from a better statistical understanding of the assumptions made (that depend on the nature of the problem) might give a better understanding of the uncertainty and risk that are connected to the question.

Kornyshova and Salinesi (2007) said that the influence of the selection of a MCDM method on the decision made is well known, as are the consequences from making a poor decision. Eldarandaly et al (2009) said that applying different MCDM methods to the same problem could often generate different outcomes. Using an 
unsuitable MCDM method can lead to poor decisions (Haddad et al, 2019). Ishizaka and Siraj (2018) stated the significance of making good decisions and said that MCDM was improving them.

This paper will apply two MCDM methods for BOEING Strategic Decisions, compare the stability of the outcomes of the methods in the presence of uncertainty ion criteria weights and performance measures and recommend the method that delivered the most stable outcome. The next two sub-sections will give a brief explanation of the MCDM methods used.

\subsection{The Analytical Hierarchy Process (AHP)}

AHP is a MCDM method developed by Thomas L. Saaty in 1971- 1975 (Saaty, 1987). AHP helps decision makers to solve a problem with multiple conflicting subjective criteria (Ishizaka \& Labib 2009) by breaking down a complex problem into simpler sub-problems then, aggregating the solutions of all sub-problems into one solution (Saaty, 1994). AHP uses expert judgments to derive priorities, and apply pairwise comparisons to measure how much one alternative dominates another with respect to a certain criterion (Saaty, 2008). Using a hierarchical structure of the criteria, AHP could allow users to focus on specific criteria and sub-criteria when providing judgments. Figure 1 shows a simple Analytical Hierarchy Process hierarchy model composed of three levels. The goal of the decision process is on the first level, the set of criteria by which alternatives are assessed are on the second level and alternatives are on the third level (Saaty, 2012). Moreover, AHP could incorporate group decision making (Omkarprasad \& Kumar, 2006). Since its development, AHP has been applied to almost all fields of decision making.

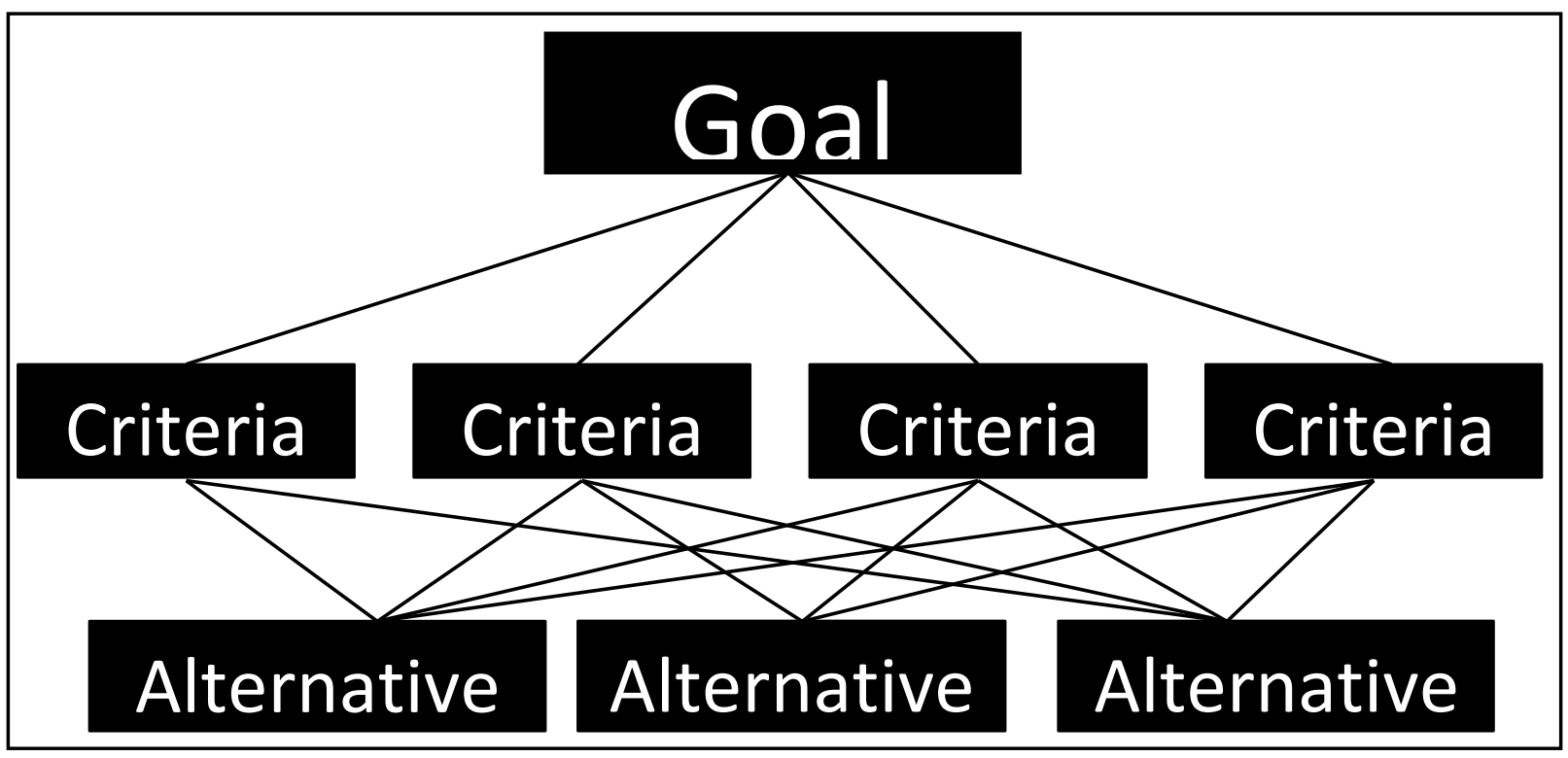

Figure 1: Simple three level decision hierarchy (Saaty, 2012)

Ishizaka and Labib (2009) identified seven steps for a decision making process using AHP:

1. Problem modelling: identify goals, criteria and alternatives.

2. Pairwise comparisons conducted on each part of the hierarchy. 
3. Judgments scale, AHP can evaluate quantitative and qualitative criteria and alternatives using the same preference scale of nine levels.

4. Priorities derivation, traditional AHP used an eigenvalue method.

5. Consistency check.

6. Aggregation of local priorities with respect to all criteria to calculate the global priorities of each alternative using Equation (1).

$P_{i}=\Sigma_{j} w_{j} \cdot l_{i j}$

Where: $P_{i}$ : global priority of the alternative $i$

$w_{j}$ : weight of the criterion $j$

$l_{i j}$ : local priority

7. Sensitivity analysis.

According to Al-Shabeeb (2015), AHP often generates good results, provides an approach to define and evaluate alternatives, and presents a powerful hierarchy model to visualize the problem. But considering a large number of alternatives and criteria makes the application of AHP time and effort consuming due to the large number of pairwise comparisons that need to be conducted.

\subsection{The Preference Ranking Organization METHod for Enrichment of Evaluations II (PROMETHEE II)}

PROMETHEE methods were developed by Jean-Pierre Brans and presented for the first time in 1982 at a conference at the Université Laval in Canada. PROMETHEE methods have been extensively studied since then.

PROMETHEE methods are outranking MCDM methods with PROMETHEE I partial ranking and PROMETHEE II total ranking of alternatives. PROMETHEE methods generally consist of a preference function representing each criterion and weights describing their relative importance. The main idea of the PROMETHEE methods is to conduct pairwise comparisons among alternatives regarding each criterion then comprehensively compare them with respect to all criteria (Xiaohann et al, 2013).

According to Brans (1982), PROMETHEE methods apply the following steps:

- Identify the problem.

- Identify a set of criteria.

- Identify information between criteria (criteria weights).

- Identify Information within criteria (pairwise comparisons and preference functions).

- Identify a set of alternatives.

- Evaluate overall score of each alternative.

Brans (1982) identified six types of preference functions and stressed that efficient alternatives were the alternatives that were non-dominated by other alternatives. The preference function used in this paper is Type 1 preference function: the usual criterion and shown in Figure 2. 


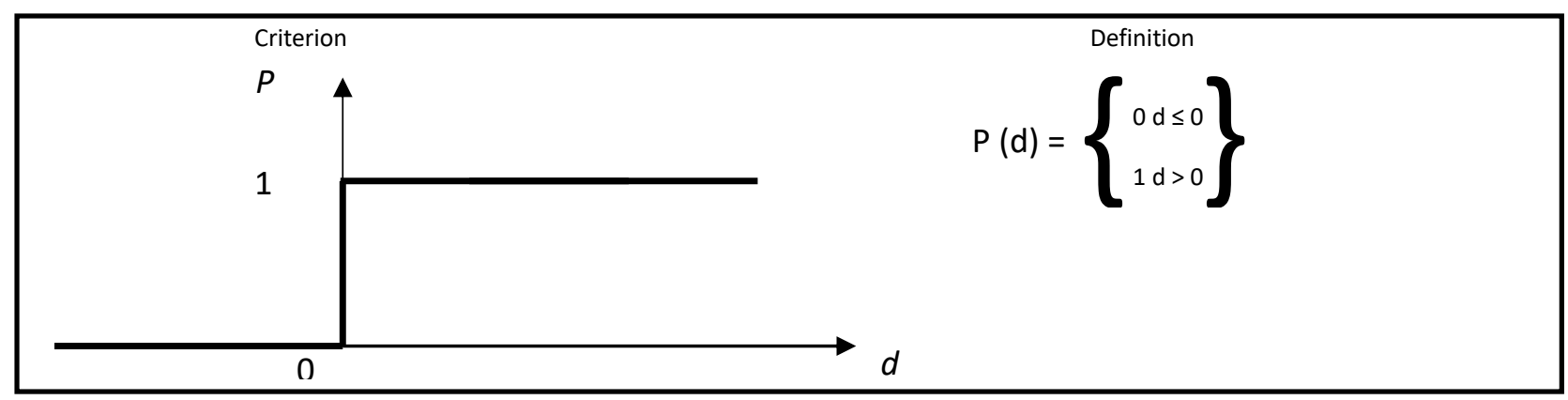

Figure 2: Usual criterion preference functions (Brans, 1982)

Each preference function identified by Brans (1982) required a number of parameters ( $q, p$, or s) to be identified where:

- $\mathrm{q}$ : is an Indifference threshold.

- $\mathrm{p}$ : is a Strict preference threshold.

- $s$ : is an Intermediate value between $q$ and $p$.

Moreover, Brans (1982) calculated the Preference Indices using Equations (2) and (3):

Let $a, b \in A$ :

$$
\begin{aligned}
& \pi(a, b)=\Sigma_{j} P_{j}(a, b) \cdot w_{j} \\
& \pi(b, a)=\Sigma_{j} P_{j}(b, a) \cdot w_{j}
\end{aligned}
$$

Where, $\pi(a, b)$ expressed the degree by which alternative a was preferred to alternative $b$, and $\pi(b, a)$ express the degree by which alternative $b$ was preferred to alternative $a$.

And

$$
\begin{aligned}
& \pi(a, a)=0 \\
& 0 \leq \pi(a, b) \leq 1 \\
& 0 \leq \pi(b, a) \leq 1 \\
& 0 \leq \pi(a, b)+\pi(b, a) \leq 1 \\
& \pi(a, b) \approx 0 \text { weak global preference of a over } b . \\
& \pi(a, b) \approx 1 \text { strong global preference of a over } b .
\end{aligned}
$$

And calculated the Positive, Negative and Net outranking flows using Equations (4), (5) and (6).

Positive outranking flow:

$$
\Phi^{+}(\mathrm{a})=1 /(\mathrm{n}-1) \sum_{(\mathrm{x} \in \mathrm{A})}[\pi(\mathrm{a}, \mathrm{x})]
$$

Negative outranking flow:

$$
\Phi^{-}(\mathrm{a})=1 /(\mathrm{n}-1) \Sigma_{(\mathrm{x} \in \mathrm{A})}[\pi(\mathrm{x}, \mathrm{a}]
$$


Net outranking flow:

$$
\Phi(\mathrm{a})=\left[\Phi^{+}(\mathrm{a})+\Phi^{-}(\mathrm{a})\right]
$$

Rather than pointing out a "correct" decision, the PROMETHEE methods aid decision makers in finding the alternative that best suits their goal and their understanding of the problem. It provides a comprehensive and rational framework for structuring a decision problem, identifying and quantifying its conflicts and synergies, and clusters of actions, and highlighting the main alternative and the structured reasoning behind the identification and quantification.

\section{New MCDM methods selection approach}

Several researchers proposed selection approaches for MCDM methods (Hobbs, 1986; Ozernoy, 1992; Vincke, 1995; Guitouni \& Martel, 1997; Ballestero \& Romero, 1998; Laaribi, 2000; Kornyshova \& Salinesi, 2007; Olson et al 2007; Ulengin et al. 2007; Eldarandaly et al 2009; Mota, 2013; Roy \& Slowinski, 2013; Saaty \& Ergu, 2015). MacCrimmon (1973) was one of the first to see the potential worth of good MCDM methods selection and to recognise a need to compare different methods. MacCrimmon put forward a proposal for classifying MCDM methods that was based on a tree diagram representing a specification chart. Illustrative examples of applications were included.

A lot of researchers have compared different MCDM methods based on the solution delivered by them but Roy \& Slowinski (2013) think that such a comparison of the final result might be "ill-founded". They encouraged users to considered MCDM methods as being a tool to provide a better understanding of decisions and decision making, and for studying, exploring and evaluating possibilities, rather than MCDM methods just being tools to make a decision. Norese (2016) suggested the advice given to users to be considered as part of the outcome provided by using a method. Zeleny (2011) said decision making was not an outcome but a decision process including definition of criteria, identification of criteria weights, identification of alternatives, evaluation and processing of information, production of outcomes, review of criteria, alternatives, and analysis of bias, uncertainty and risk, then review and validate the process and repeat until a satisfactory outcome is produced.

Many factors could affect the selection of MCDM methods. A decision maker may have some previous experience or knowledge about some of them, the methods might be randomly selected, or they may just be easily available (Laaribi, 2000; Kornyshova \& Salinesi, 2007; Ulengin et al 2007). A number of researchers have suggested ways of selecting a MCDM method but there is not well-structured way of selecting MCDM methods in the literature.

Haddad et al (2019) created a new structured approach as a part of broader research and factors to be addressed when selecting MCDM methods were found, including MCDM methods' characteristics and problem characteristics. If these factors were addressed then a framework could be created that might provide decision makers with a group of suitable potential MCDM methods that would be appropriate for their 
problem. In the research described this paper, MCDM methods that consider discrete sets of alternatives were considered. Sensitivity analysis was applied to the candidate methods and a MCDM method was selected that provided the most robust outcome (dependant on the decision makers' anticipation of uncertainty and risk factors).

A decision-maker needs to provide information about the validity of the model, the outcome, and method used (Scholten et al, 2015). The concept of optimal solution might differ from the concept of robustness. Groves and Lempert (2007) suggested using robust decision making to address the problem of severe uncertainty and risk. Researchers have acknowledged the need for robustness and Simon (1979) described it as the "good and not too risky", while Vincke (1999) said it is a robust alternative that achieves a "minimum performance". Comes et al (2010) identified a robust alternative as the alternative that performed "sufficiently well" for a broad variety of scenarios i.e. achieved the minimum required thresholds of performance for a set of criteria for all scenarios. While Comes et al (2013) identified the concept of robustness as a decision-maker preferring an alternative that guaranteed satisfactory performance over an alternative that maximized the performance in one "Best Scenario". Vincke (1999) described robustness as relative, depending on the method or the problem, he said robustness could be used to "choose and refine" methods.

Haddad et al (2019) said that weights assigned to criteria characterize the importance of the criteria, thus identifying the critical criteria and accurately re-evaluating their weight could improve the decision-making process. They proposed a framework to determine the minimum percentage change required in criteria weights to change the ranking of any two alternatives, and, the minimum percentage change required in performance measure to change the ranking of any two alternatives "in terms of a single decision criterion at a time".

A new set of propositions that consider four generalized MCDM problem SITUATIONs are proposed by the authors to be related to the Boeing strategic decision:

SITUATION ONE: Decision makers are not certain of the criteria weights and / or anticipate a high and severe risk factor that could affect the weights of the criteria.

SITUATION TWO: If decision makers were uncertain of performance measures and / or anticipate a risk factor of high severity that could affect performance measures.

SITUATION THREE: If decision makers were uncertain and / or anticipate a risk factor of high severity that could affect both criteria weights and performance measures.

Comes et al (2013) differentiated between two types of decision-making by identifying the type of uncertainty involved: 
- Decision-making under ignorance where severe uncertainty were characterized by ignorance

- Decision-making under risk where probability functions were known

Moreover Comes (2013) suggested using fuzzy set theory and rough set theory to deal with internal uncertainties. Stewart (2005) suggested proper problem structuring, appropriate sensitivity and risk analysis to deal with internal uncertainty, stressed that deep internal uncertainties cannot be resolved by proper problem structuring and encouraged using sensitivity and robustness analysis to deal with it.

Vanderpas et al (2010) claimed that if sensitivity analysis was used to deal with deep uncertainty involved in a decision process then, an understanding of the relevant uncertainty space and all the uncertainties involved in the decision process will be needed.

\section{Boeing Strategic Market Decision}

China and India led the Asian region to become the world's largest aviation market with regard to international departures and international freight in the last decade (Arjomandia et al, 2018). The threat posed by Airbus to the commercial jet aircraft market that was dominated by Boeing is considered. This problem evaluated the market attractiveness and competitive strength of Boeing in four global markets. A set of twenty-four criteria were identified.

Factors addressed considered the changing nature of airline needs and the international business environment. Market attractiveness included political climate, competitive intensity, growth and size. The competitive strength in each of the four regions was assessed based on relative market share, price competition, aircraft quality, and customer knowledge of each type of aircraft.

The set of criteria were:

$\mathrm{C}_{1}$ : Market size for $115-150$ passengers plane

$C_{2}$ : Market size for $175-210$ passengers plane

$C_{3}$ : Market size for 260 and more passengers plane

$\mathrm{C}_{4}$ : Market growth rate for $115-150$ passengers plane

$C_{5}$ : Market growth rate for $175-210$ passengers plane

$C_{6}$ : Market growth rate for 260 and more passengers plane

$C_{7}$ : Market competitive intensity for $115-150$ passengers plane

$C_{8}$ : Market competitive intensity for $175-210$ passengers plane

$C_{9}$ : Market competitive intensity for 260 and more passengers plane

$\mathrm{C}_{10}$ : Political factors enhancing the market size for $115-150$ passengers plane

$C_{11}$ : Political factors enhancing the market size for $175-210$ passengers plane

$C_{12}$ : Political factors enhancing the market size for 260 and more passengers plane

$\mathrm{C}_{13}$ : Market share for $115-150$ passengers plane

$\mathrm{C}_{14}$ : Market share for $175-210$ passengers plane

$C_{15}$ : Market share for 260 and more passengers plane

$C_{16}$ : Price competition for $115-150$ passengers plane

$\mathrm{C}_{17}$ : Price competition for $175-210$ passengers plane

$\mathrm{C}_{18}$ : Price competition for 260 and more passengers plane

$\mathrm{C}_{19}$ : Product quality for $115-150$ passengers plane 
$C_{20}$ : Product quality for $175-210$ passengers plane

$C_{21}$ : Product quality for 260 and more passengers plane

$\mathrm{C}_{22}$ : Customer knowledge for $115-150$ passengers plane

$\mathrm{C}_{23}$ : Customer knowledge for $175-210$ passengers plane

$\mathrm{C}_{24}$ : Customer knowledge for 260 and more passengers plane

The set of alternatives that represented the global market regions were:

$A_{1}:$ United States

$A_{2}$ : Asia

$A_{3}$ : Europe

$\mathrm{A}_{4}$ : Middle East

Criteria weights and performance measures for alternatives with respect to criteria are shown as a decision matrix in Table 1.

Table 1: Decision matrix for Boeing Strategic Market Decisions Example

\begin{tabular}{|c|c|c|c|c|}
\hline $\begin{array}{ll}\text { Criteria } & \text { Alternative } \\
\end{array}$ & $\begin{array}{c}A_{1} \\
\text { USA }\end{array}$ & $\begin{array}{c}\mathrm{A}_{2} \\
\text { Asia }\end{array}$ & $\begin{array}{c}\mathrm{A}_{3} \\
\text { Europe }\end{array}$ & $\begin{array}{c}\mathrm{A}_{4} \\
\text { Middle East }\end{array}$ \\
\hline $\mathrm{C}_{1}$ : Market size for $115-150$ passengers $=0.073$ & 0.471 & 0.209 & 0.215 & 0.106 \\
\hline$C_{2}:$ Market size for $175-210$ passengers $=0.021$ & 0.471 & 0.209 & 0.215 & 0.106 \\
\hline$C_{3}:$ Market size for +260 passengers $=0.032$ & 0.317 & 0.426 & 0.174 & 0.083 \\
\hline$C_{4}:$ Market growth rate for $115-150$ passengers $=0.161$ & 0.130 & 0.546 & 0.119 & 0.205 \\
\hline$C_{5}:$ Market growth rate for $175-210$ passengers $=0.047$ & 0.130 & 0.546 & 0.119 & 0.205 \\
\hline$C_{6}:$ Market growth rate for +260 passengers $=0.070$ & 0.083 & 0.608 & 0.124 & 0.185 \\
\hline $\mathrm{C}_{7}:$ Market competitive for $115-150$ passengers $=0.016$ & 0.499 & 0.284 & 0.083 & 0.134 \\
\hline$C_{8}:$ Market competitive for $175-210$ passengers $=0.007$ & 0.499 & 0.284 & 0.083 & 0.134 \\
\hline$C_{9}:$ Market competitive for +260 passengers $=0.010$ & 0.499 & 0.284 & 0.083 & 0.134 \\
\hline $\begin{array}{l}C_{10}: \text { Political factors enhancing market size for } 115-150 \\
\text { passengers }=0.021\end{array}$ & 0.656 & 0.217 & 0.049 & 0.078 \\
\hline $\begin{array}{l}C_{11}: \text { Political factors enhancing market size for } 175-210 \\
\text { passengers }=0.021\end{array}$ & 0.656 & 0.217 & 0.049 & 0.078 \\
\hline $\begin{array}{l}\mathrm{C}_{12}: \text { Political factors enhancing market size for }+260 \\
\text { passengers }=0.021\end{array}$ & 0.656 & 0.217 & 0.049 & 0.078 \\
\hline$C_{13}:$ Market share for $115-150$ passengers $=0.013$ & 0.527 & 0.280 & 0.086 & 0.107 \\
\hline$C_{14}:$ Market share for $175-210$ passengers $=0.006$ & 0.527 & 0.280 & 0.086 & 0.107 \\
\hline$C_{15}:$ Market share for +260 passengers $=0.008$ & 0.517 & 0.333 & 0.075 & 0.075 \\
\hline$C_{16}:$ Price competition for $115-150$ passengers $=0.052$ & 0.498 & 0.284 & 0.097 & 0.121 \\
\hline$C_{17}:$ Price competition for $175-210$ passengers $=0.030$ & 0.498 & 0.284 & 0.097 & 0.121 \\
\hline $\mathrm{C}_{18}:$ Price competition for +260 passengers $=0.048$ & 0.498 & 0.284 & 0.097 & 0.121 \\
\hline $\mathrm{C}_{19}:$ Product quality for $115-150$ passengers $=0.094$ & 0.250 & 0.250 & 0.250 & 0.250 \\
\hline$C_{20}:$ Product quality for $175-210$ passengers $=0.094$ & 0.250 & 0.250 & 0.250 & 0.250 \\
\hline$C_{21}:$ Product quality for +260 passengers $=0.094$ & 0.250 & 0.250 & 0.250 & 0.250 \\
\hline$C_{22}:$ Customer knowledge for $115-150$ passengers $=0.022$ & 0.457 & 0.329 & 0.095 & 0.119 \\
\hline$C_{23}:$ Customer knowledge for $175-210$ passengers $=0.016$ & 0.457 & 0.329 & 0.095 & 0.119 \\
\hline$C_{24}:$ Customer knowledge for +260 passengers plane $=0.021$ & 0.457 & 0.329 & 0.095 & 0.119 \\
\hline
\end{tabular}

The Novel MCDM Methods Selection Framework was applied as shown in Figure 3. The nature of the alternative set was considered to be "Discrete" because the alternative consisted of integer values. Inputs considered in this numerical example were quantitative. All input information was deterministic. The aim behind applying MCDM methods to this problem was to rank the set of alternatives using pairwise comparisons to achieve a total order of alternatives. An absolute criteria measure scale was used considering a preference structure between alternatives. 


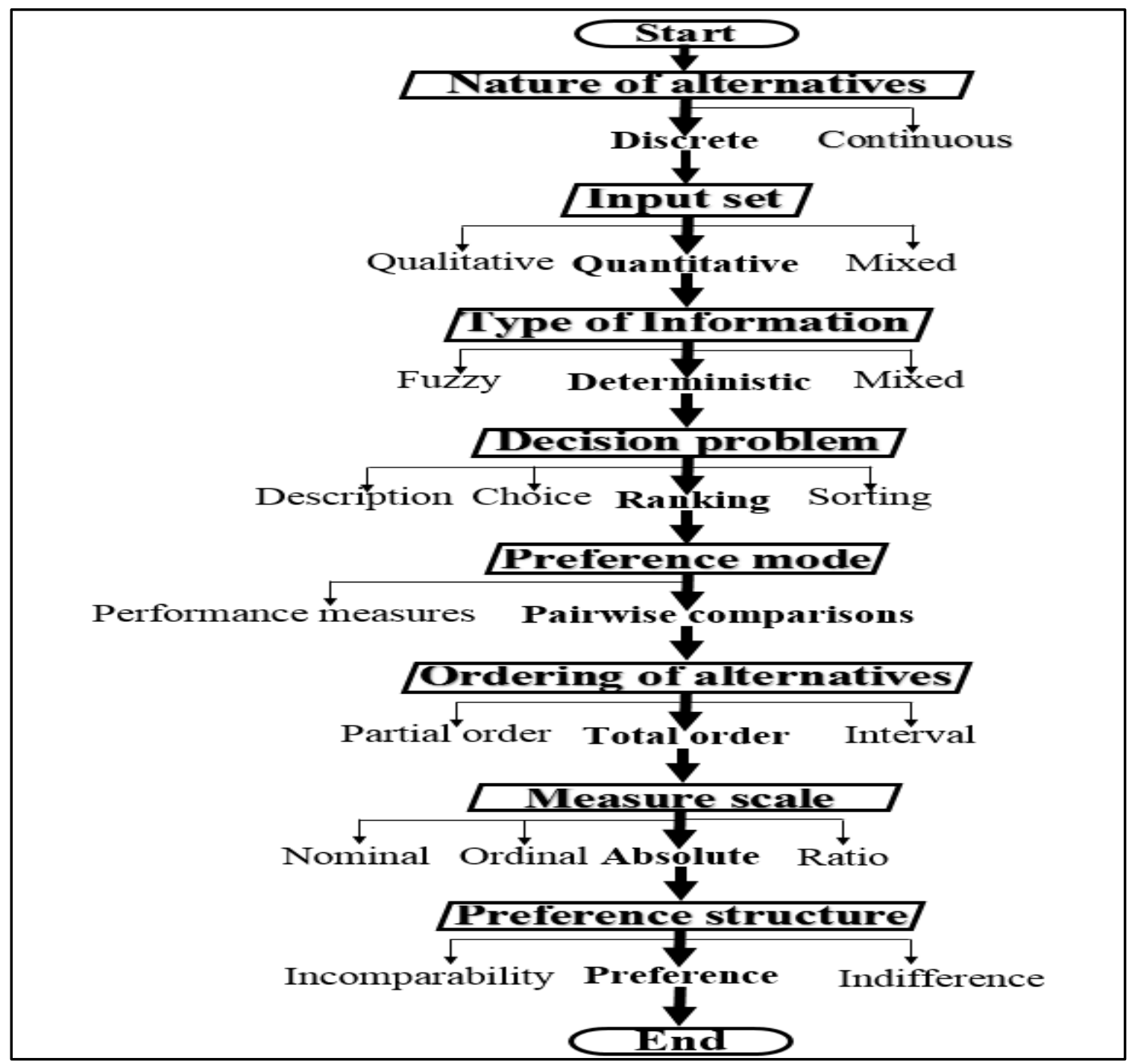

Figure 3: New MCDM Methods Selection Framework branch for BOEING Strategic Market Decisions Example

A screen shot of the user interface of the structured MCDM Methods Selection Framework is shown in Figure 5. A group of candidate methods were suitable for this problem as shown at the bottom left the screen shot shown in Figure 4 and listed here:

- The Analytical Hierarchy Process (AHP)

- The Best Worst Method (BWM)

- Preference Ranking Organization METHod for Enrichment Evaluations II, (PROMETHEE II)

- Elimination Et Choix Traduisant la Realite III, (Elimination and Choice Expressing Reality III), (ELECTREE III) 


\section{MCDM Methods Selection Software}

\section{Problem Features}

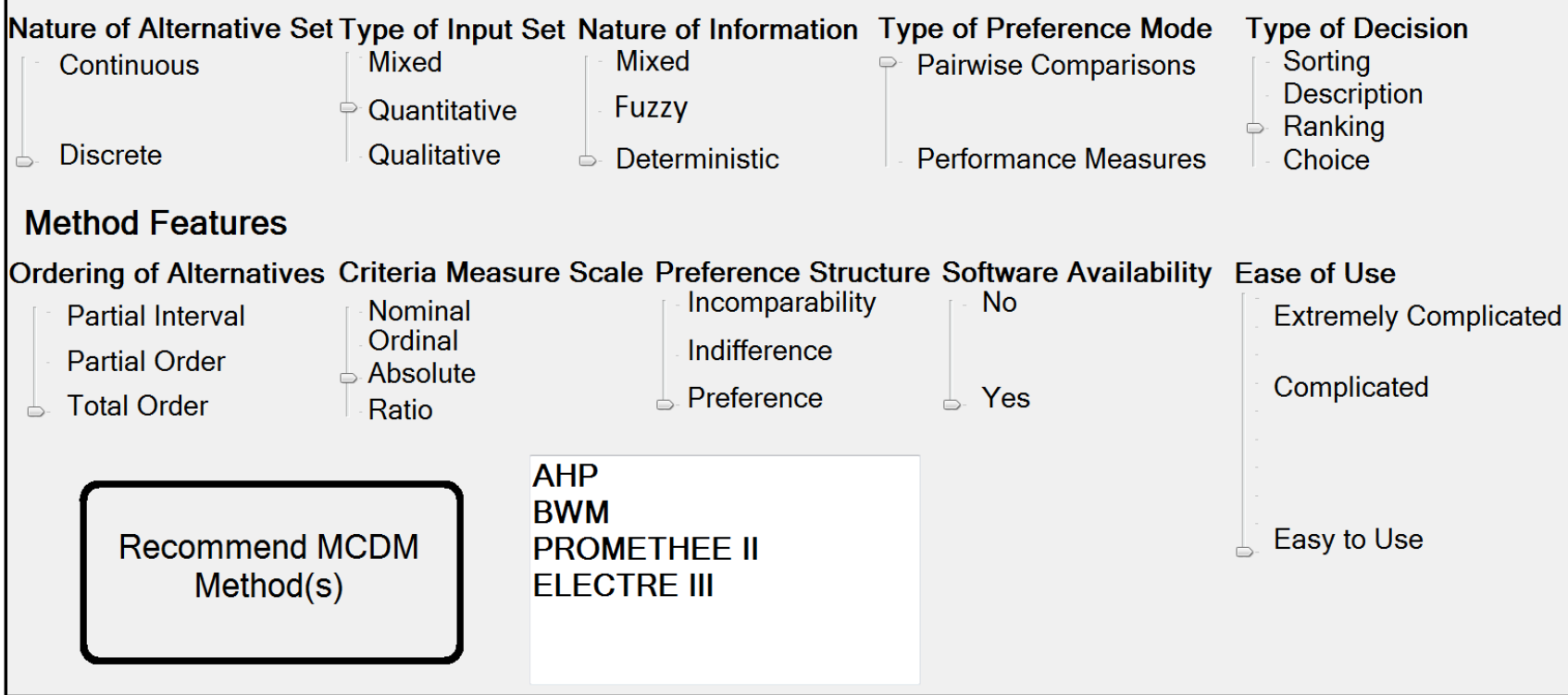

Figure 4: Screen Shot of the New MCDM Methods Selection Framework for BOEING Strategic Market Decisions Example

AHP and PROMETHE II methods were selected as examples. AHP provided the following ranking of alternatives: $A_{2}>A_{1}>A_{4}>A_{3}$, with a global score of alternatives: $A_{1}=0.308, A_{2}=0.322, A_{3}=0.180$ and $A_{4}=$ 0.191. PROMETHEE II provided the same ranking of alternatives: $A_{2}>A_{1}>A_{4}>A_{3}$, with a net flow of alternatives: $\Phi\left(A_{1}\right)=0.278, \Phi\left(A_{2}\right)=0.384, \Phi\left(A_{3}\right)=-0.521$ and $\Phi\left(A_{4}\right)=-0.140$.

Although AHP and PROMETHEE II methods delivered the same ranking of alternatives, sensitivity analysis was conducted on both methods' outcomes to recommend the method that best suited this problem and provided the most robust outcome. Minimum percentage change required to alter the ranking of alternatives for the most critical criterion weight and the most critical performance measures were calculated. Results are shown in Tables 2, 3, 4 and 5. Non-feasible value where $\pm 100 \%$ change in the value of that performance measure did not affect the original ranking of the alternatives were not listed in the tables.

The most critical criterion using AHP was the fourth criterion $\left(C_{4}\right)$ that represented Market growth rate for 115150 passengers signified by the smallest value (bold number) in Table 2 . This value represented the minimum percentage change required in the weight of the Market growth rate for the 115-150 passengers criterion to change the ranking of alternatives one and two $\left(A_{1}>A_{2}\right)$. A 19.255\% decrease in its weight preferred the United States market region $\left(A_{1}\right)$ to Asia market region $\left(A_{2}\right)$.

Table 2: Minimum percentage change in criteria weights for Boeing Strategic Market Decisions Example using AHP

\begin{tabular}{|l|l|l|}
\hline \multicolumn{1}{|c|}{ Criteria } & \multicolumn{1}{c|}{ Percentage change } & \multicolumn{1}{c|}{ New Ranking } \\
\hline$C_{1}:$ Market size for 115-150 passengers & 67.123 & $A_{1}>A_{2}>A_{4}>A_{3}$ \\
\hline$C_{2}:$ Market size for 175-210 & 242.857 & $A_{1}>A_{2}>A_{4}>A_{3}$ \\
\hline$C_{3}:$ Market size for +260 passengers & 340.625 & $A_{2}>A_{1}>A_{3}>A_{4}$ \\
\hline$C_{4}:$ Market growth rate for 115-150 passengers & \multicolumn{1}{|c|}{$-\mathbf{1 9 . 2 5 5}$} & \multicolumn{1}{c|}{$A_{1}>A_{2}>A_{4}>A_{3}$} \\
\hline$C_{5}:$ Market growth rate for 175-210 passengers & -76.596 & $A_{1}>A_{2}>A_{4}>A_{3}$ \\
\hline$C_{6}:$ Market growth rate for +260 passengers & -38.571 & $A_{1}>A_{2}>A_{4}>A_{3}$ \\
\hline$C_{7}:$ Market competitive for 115-150 passengers & 375 & $A_{1}>A_{2}>A_{4}>A_{3}$ \\
\hline$C_{8}:$ Market competitive for 175-210 passengers & 871.429 & $A_{1}>A_{2}>A_{4}>A_{3}$ \\
\hline$C_{9}:$ Market competitive for +260 passengers & 610 & $A_{1}>A_{2}>A_{4}>A_{3}$ \\
\hline
\end{tabular}




\begin{tabular}{|l|l|l|}
\hline$C_{10}:$ Political factors enhancing market size for 115-150 passengers & 142.857 & $A_{1}>A_{2}>A_{4}>A_{3}$ \\
\hline$C_{11}:$ Political factors enhancing market size for 175-210 passengers & 142.857 & $A_{1}>A_{2}>A_{4}>A_{3}$ \\
\hline$C_{12}:$ Political factors enhancing market size for +260 passengers & 142.857 & $A_{1}>A_{2}>A_{4}>A_{3}$ \\
\hline$C_{13}:$ Market share for 115-150 passengers & 407.692 & $A_{1}>A_{2}>A_{4}>A_{3}$ \\
\hline$C_{14}:$ Market share for 175-210 passengers & 883.333 & $A_{1}>A_{2}>A_{4}>A_{3}$ \\
\hline$C_{15}:$ Market share for +260 passengers & 875 & $A_{1}>A_{2}>A_{4}>A_{3}$ \\
\hline$C_{16}:$ Price competition for 115-150 passengers & 113.462 & $A_{1}>A_{2}>A_{4}>A_{3}$ \\
\hline$C_{17}:$ Price competition for 175-210 passengers & 200 & $A_{1}>A_{2}>A_{4}>A_{3}$ \\
\hline$C_{18}:$ Price competition for +260 passengers & 118.75 & $A_{1}>A_{2}>A_{4}>A_{3}$ \\
\hline$C_{19}:$ Product quality for 115-150 passengers & 963.830 & $A_{1}=A_{2}=A_{3}=A_{4}$ \\
\hline$C_{20}:$ Product quality for 175-210 passengers & 963.830 & $A_{1}=A_{2}=A_{3}=A_{4}$ \\
\hline$C_{21}:$ Product quality for +260 passengers & 963.830 & $A_{1}=A_{2}=A_{3}=A_{4}$ \\
\hline$C_{22}:$ Customer knowledge for 115-150 passengers & $A_{1}>A_{2}>A_{4}>A_{3}$ \\
\hline$C_{23}:$ Customer knowledge for 175-210 passengers & 431.818 & $A_{1}>A_{2}>A_{4}>A_{3}$ \\
\hline$C_{24}:$ Customer knowledge for +260 passengers & 606.250 & $A_{1}>A_{2}>A_{4}>A_{3}$ \\
\hline
\end{tabular}

The most critical criterion PROMETHEE II was the fourth criterion $\left(C_{4}\right)$ that represented Market growth rate for 115-150 passengers signified by the smallest value (bold number) in Table 3. This value represented the minimum percentage change required in the weight of the Market growth rate for 115-150 passengers to change the ranking of alternatives one and two $\left(A_{1}>A_{2}\right)$. $A 50.311 \%$ decrease in its weight preferred the United States market region $\left(A_{1}\right)$ to Asia market region $\left(A_{2}\right)$.

Table 3: Minimum percentage change in criteria weights for Boeing Strategic Market Decisions Example using PROMETHEE II

\begin{tabular}{l} 
Table 3: Minimum percentage change in criteria weights for Boeing Strategic Market Decisions Example using PROMETHEE I \\
\begin{tabular}{|l|l|l|}
\hline \multicolumn{1}{|c|}{ Criteria } & \multicolumn{1}{|c|}{ Percentage change } & \multicolumn{1}{c|}{ New Ranking } \\
\hline$C_{1}$ & 105.479 & $A_{1}>A_{2}>A_{4}>A_{3}$ \\
\hline$C_{2}$ & 376.190 & $A_{1}>A_{2}>A_{4}>A_{3}$ \\
\hline$C_{3}$ & $1118.75 \quad-50.311$ & $A_{2}>A_{4}>A_{1}>A_{4}$ \\
\hline \multicolumn{1}{|c|}{$C_{4}$} & \multicolumn{1}{|c|}{$A_{1}>A_{2}>A_{4}>A_{3}$} \\
\hline$C_{5}$ & 793.617 & $A_{2}>A_{4}>A_{1}>A_{3}$ \\
\hline$C_{6}$ & 328.571 & $A_{2}>A_{4}>A_{1}>A_{3}$ \\
\hline$C_{7}$ & 900 & $A_{1}>A_{2}>A_{4}>A_{3}$ \\
\hline$C_{8}$ & 2042.857 & $A_{1}>A_{2}>A_{4}>A_{3}$ \\
\hline$C_{9}$ & 1400 & $A_{1}>A_{2}>A_{4}>A_{3}$ \\
\hline$C_{10}$ & 661.905 & $A_{1}>A_{2}>A_{4}>A_{3}$ \\
\hline$C_{11}$ & 661.905 & $A_{1}>A_{2}>A_{4}>A_{3}$ \\
\hline$C_{12}$ & 661.905 & $A_{1}>A_{2}>A_{4}>A_{3}$ \\
\hline$C_{13}$ & 1053.846 & $A_{1}>A_{2}>A_{4}>A_{3}$ \\
\hline$C_{14}$ & 2400 & $A_{1}>A_{2}>A_{4}>A_{3}$ \\
\hline$C_{15}$ & 1775 & $A_{1}>A_{2}>A_{4}>A_{3}$ \\
\hline$C_{16}$ & 265.385 & $A_{1}>A_{2}>A_{4}>A_{3}$ \\
\hline$C_{17}$ & 466.667 & $A_{1}>A_{2}>A_{4}>A_{3}$ \\
\hline$C_{18}$ & 275 & $A_{1}>A_{2}>A_{4}>A_{3}$ \\
\hline$C_{19}$ & 963.830 & $A_{1}=A_{2}=A_{3}=A_{4}$ \\
\hline$C_{20}$ & 963.830 & $A_{1}=A_{2}=A_{3}=A_{4}$ \\
\hline$C_{21}$ & 963.830 & $A_{1}=A_{2}=A_{3}=A_{4}$ \\
\hline$C_{22}$ & 627.273 & $A_{1}>A_{2}>A_{4}>A_{3}$ \\
\hline$C_{23}$ & 900 & $A_{1}>A_{2}>A_{4}>A_{3}$ \\
\hline$C_{24}$ & 661.905 & $A_{1}>A_{2}>A_{4}>A_{3}$ \\
\hline & & \\
\hline
\end{tabular} \\
\hline
\end{tabular}

The most critical performance measures using AHP were $\left(A_{4} C_{19}, A_{4} C_{20}\right.$ and $\left.A_{4} C_{21}\right)$, signified by the smallest values (bold numbers) in Table 4. These values represented the minimum percentage change required in the value of their performance measures to change the ranking of alternatives three and four, Europe and the Middle East $\left(A_{3}>A_{4}\right)$. A 25\% decrease in the values of their performance measures changed the preference from the Middle East region to Europe.

Table 4: Minimum percentage change in performance measures for Boeing Strategic Market Decisions Example using AHP \begin{tabular}{l|l|l} 
Performance Measure & Percentage & New ranking
\end{tabular} 


\begin{tabular}{|c|c|c|}
\hline$A_{3} C_{1}$ & 57 & $A_{2}>A_{1}>A_{3}>A_{4}$ \\
\hline$A_{3} C_{3}$ & -82 & $A_{1}>A_{2}>A_{4}>A_{3}$ \\
\hline$A_{1} C_{4}$ & 71 & $A_{1}>A_{2}>A_{4}>A_{3}$ \\
\hline $\mathrm{A}_{2} \mathrm{C}_{4}$ & -30 & $A_{1}>A_{2}>A_{4}>A_{3}$ \\
\hline$A_{3} C_{4}$ & 65 & $A_{2}>A_{1}>A_{3}>A_{4}$ \\
\hline $\mathrm{A}_{4} \mathrm{C}_{4}$ & -41 & $A_{2}>A_{1}>A_{3}>A_{4}$ \\
\hline$A_{2} C_{5}$ & -59 & $A_{1}>A_{2}>A_{4}>A_{3}$ \\
\hline $\mathrm{A}_{2} \mathrm{C}_{6}$ & -55 & $A_{1}>A_{2}>A_{4}>A_{3}$ \\
\hline $\mathrm{A}_{1} \mathrm{C}_{19}$ & 39 & $A_{1}>A_{2}>A_{4}>A_{3}$ \\
\hline $\mathrm{A}_{2} \mathrm{C}_{19}$ & -32 & $A_{1}>A_{2}>A_{4}>A_{3}$ \\
\hline $\mathrm{A}_{3} \mathrm{C}_{19}$ & 30 & $A_{2}>A_{1}>A_{3}>A_{4}$ \\
\hline $\mathrm{A}_{4} \mathrm{C}_{19}$ & -25 & $A_{2}>A_{1}>A_{3}>A_{4}$ \\
\hline $\mathrm{A}_{1} \mathrm{C}_{20}$ & 39 & $A_{1}>A_{2}>A_{4}>A_{3}$ \\
\hline $\mathrm{A}_{2} \mathrm{C}_{20}$ & -32 & $A_{1}>A_{2}>A_{4}>A_{3}$ \\
\hline $\mathrm{A}_{3} \mathrm{C}_{20}$ & 30 & $A_{2}>A_{1}>A_{3}>A_{4}$ \\
\hline$A_{4} C_{20}$ & -25 & $A_{2}>A_{1}>A_{3}>A_{4}$ \\
\hline $\mathrm{A}_{1} \mathrm{C}_{21}$ & 39 & $A_{1}>A_{2}>A_{4}>A_{3}$ \\
\hline $\mathrm{A}_{2} \mathrm{C}_{21}$ & -32 & $A_{1}>A_{2}>A_{4}>A_{3}$ \\
\hline $\mathrm{A}_{3} \mathrm{C}_{21}$ & 30 & $A_{2}>A_{1}>A_{3}>A_{4}$ \\
\hline $\mathrm{A}_{4} \mathrm{C}_{21}$ & -25 & $A_{2}>A_{1}>A_{3}>A_{4}$ \\
\hline
\end{tabular}

The most critical performance measures using PROMETHEE II were $\left(A_{1} C_{19}, A_{2} C_{19} A_{1} C_{20}, A_{2} C_{20}, A_{1} C_{21}\right.$ and $\left.A_{2} C_{21}\right)$, signified by the smallest values (bold numbers) in Table 5 . These values represented the minimum percentage change required in the values of performance measures $\left(A_{1} C_{19}\right),\left(A_{2} C_{19}\right),\left(A_{1} C_{20}\right),\left(A_{2} C_{20}\right),\left(A_{1} C_{21}\right)$ or $\left(A_{2} C_{21}\right)$ to change the ranking of the alternatives one and two, the United States and $A s i a\left(A_{1}>A_{2}\right)$. $A 1 \%$ increase in the value of their performance measures changed the preference from Asia to the United States. A 1\% decrease in the value of their performance measures changed the preference from Asia to the United States.

Table 5: Minimum percentage change in performance measures for Boeing Strategic Market Decisions Example using PROMETHEE II

\begin{tabular}{|c|c|c|}
\hline Performance Measure & Percentage change & New ranking \\
\hline $\mathrm{A}_{1} \mathrm{C}_{4}$ & 47 & $A_{1}>A_{2}>A_{4}>A_{3}$ \\
\hline $\mathrm{A}_{2} \mathrm{C}_{4}$ & -44 & $A_{1}>A_{2}>A_{4}>A_{3}$ \\
\hline $\mathrm{A}_{4} \mathrm{C}_{4}$ & 99 & $A_{1}>A_{2}>A_{4}>A_{3}$ \\
\hline $\mathrm{A}_{2} \mathrm{C}_{5}$ & -63 & $A_{1}>A_{2}>A_{4}>A_{3}$ \\
\hline $\mathrm{A}_{2} \mathrm{C}_{6}$ & -72 & $A_{1}>A_{2}>A_{4}>A_{3}$ \\
\hline$A_{1} C_{19}$ & 1 & $A_{1}>A_{2}>A_{4}>A_{3}$ \\
\hline$A_{2} C_{19}$ & -1 & $A_{1}>A_{2}>A_{4}>A_{3}$ \\
\hline$A_{1} C_{20}$ & 1 & $A_{1}>A_{2}>A_{4}>A_{3}$ \\
\hline $\mathrm{A}_{2} \mathrm{C}_{20}$ & -1 & $A_{1}>A_{2}>A_{4}>A_{3}$ \\
\hline$A_{1} C_{21}$ & 1 & $A_{1}>A_{2}>A_{4}>A_{3}$ \\
\hline$A_{2} C_{21}$ & -1 & $A_{1}>A_{2}>A_{4}>A_{3}$ \\
\hline
\end{tabular}

This problem provided examples of three SITUATIONs listed in Section 2 and actions were considered to address them:

SITUATION ONE: AHP and PROMETHEE II delivered the same outcome. AHP required a $19.255 \%$ decrease to the value of most critical criterion weight (Market growth rate for 115-150 passengers) to alter the ranking of alternatives, while PROMETHEE II required a 50.311\% decrease in the value of the most critical criterion weight (Market growth rate for 115-150 passengers) to alter the ranking of alternatives. PROMETHEE II was 2.613 times less sensitive to changes in the value of the most critical criterion weight than AHP. Decision makers often prefer a method that is resilient to changes in criteria weights and often apply MCDM methods to aid them in delivering strategic decisions and long-term planning (Razmak \& Aouni, 2015). A robust method provides more stable outcomes with less sensitivity to risk and uncertainties. PROMETHEE II would be 
recommended for this problem when decision makers were uncertain of criteria weights or anticipated a risk factor of high severity that could affect criteria weights.

SITUATION TWO: AHP required a $25 \%$ increase in the values of the most critical performance measures to alter the ranking of the alternatives. PROMETHEE II required a $1 \%$ change to the values of the most critical performance measures to alter the ranking of the alternatives. AHP was 25 times less sensitive than PROMETHEE II to changes in the values of the most critical performance measures. Decision makers often prefer a method that is less sensitive to changes in the values of the performance measures and often apply MCDM methods to aid them in delivering strategic decisions and long-term planning (Razmak \& Aouni, 2015). A robust method provides more stable outcomes with less sensitivity to risk and uncertainties. AHP would be recommended for this problem when decision makers were uncertain of performance measures or anticipated a risk factor of high severity that could affect performance measures.

SITUATION THREE: PROMETHEE II was less sensitive than AHP to changes in the value of the most critical criterion weight and required a $50.311 \%$ change to the value of the most critical criterion weight to change the ranking of the alternatives. AHP was less sensitive than PROMETHEE to changes in the values of the most critical performance measures and required a $25 \%$ change to the values of the most critical performance measures to change the ranking of the alternatives. The number of the most critical criteria and the most critical performance measures a method has for a problem provides guidance about the number of risk factors the method is vulnerable towards. The higher the number of the most critical criteria and the most critical performance measures, the higher the number of risk factors a method is sensitive towards that might change the final outcome. Moreover, the lower the minimum percentage change required in the most critical criteria and the most critical performance measure, the higher the sensitivity of the outcome of a method to changes in the inputs. In this case, the best compromise between minimum percentage change required in the most critical performance measures and the most critical criteria should be made. Recommending AHP for this problem would provide a more robust outcome with less vulnerability to risk and uncertainty.

\section{Discussion}

Different methods might provide different outputs when applied to the same problem, this was because methods deal differently with performance measures, and criteria weights often have different impact from one method to another, moreover in MCDM problems a "correct" result does not exist (Tscheikner-Gratl et al, 2017). If two methods delivered significantly different results then, at least one method was invalid (Haddad et al, 2019). MCDM methods deliver a best compromise solution.

Two popular MCDM methods were applied to Boeing strategic decision, the selected methods were based on two different backgrounds and followed two different schools. AHP was based on pairwise comparisons between alternatives and followed the American school while PROMETHEE II was based on outranking relations among alternatives and followed the European school. Other methods could be considered in the 
future such as methods based on Multi Attribute Value Theory (MAVT) examples of these methods are: Weighted Sum Method (WSM), Weighted Product Method (WPM) and Weighted Aggregated Sum Product ASsessment (WASPAS) method.

This paper modelled uncertainty as percentage change in criteria weights and performance measures. Uncertainty could be modelled using different approaches and for example for example: probability functions or fuzzy number. Applying sensitivity analysis to one input factor at a time may not be enough and MonteCarlo simulation might model the uncertainty of more than one input factor at a time.

This paper considered a Boeing strategic decision. Analysing the results, and results from other problems, a set of propositions has been suggested.

In each case the following method was used:

- Qualitative and quantitative risk analysis was conducted first.

- The new MCDM Methods Selection Framework was applied to that problem to provide a subset of candidate methods suitable for that problem.

- Sensitivity analysis was conducted on the subset of candidate methods.

- Results from sensitivity analysis and risk analysis were used to recommend a method that was least sensitive to factors highlighted by the qualitative and quantitative risk analysis.

- A MCDM method could be recommended for a problem even though it was highly sensitive to changes in a certain factor, but that factor might not be highlighted during the risk analysis. Also a MCDM method might be excluded from the subset of candidate methods if it was sensitive to factors highlighted by the risk analysis.

Some potential MCDM scenarios were presented in this paper that could be generalized from the Boeing decision process. From these scenarios a new set of propositions can be stated:

PROPOSITION ONE - Uncertainty in Criteria Weights: If decision makers are uncertain and / or anticipate a risk factor of high severity that could affect:

- Market size

- Growth rate

- Political factors

- Market competitiveness

- Market share

- Price competitiveness

- Product quality

- Customer knowledge

Then a method that is less sensitive to changes in these factors should be recommended for the problem. If methods had the same sensitivity to uncertainty in these factors, then the method that had fewer critical factors should be recommended for the problem. 
PROPOSITION TWO - Uncertainty in Performance Measures: If decision makers are uncertain and / or anticipate a risk factor of high severity that could affect their statistics on the global market regions with respect to the factors mentioned in PROPOSITION ONE, then a method that is less sensitive to changes in these factors should be recommended for the problem. If methods had the same sensitivity to uncertainty, then the method that had fewer critical factors should be recommended for the problem.

PROPOSITION THREE - Uncertainty in Inputs: If decision makers are uncertain and / or anticipate a risk factor of high severity that could affect both factors mentioned in PROPOSITION ONE and PROPOSITION TWO, then a method that is least sensitive to changes in these factors should be recommended for the problem. If methods had the same sensitivity to these factors, then the method that had fewer critical input factors should be recommended for the problem and a best compromise between these factors would be conducted.

\section{Conclusions}

PROMETHEE II would be recommended for this Boeing strategic decision if decision makers were uncertain of criteria weights or anticipated a risk factor of high severity that could affect criteria weights. AHP would be recommended for this Boeing strategic decision if decision makers were uncertain of performance measures or anticipated a risk factor of high severity that could affect performance measures. If decision makers were uncertain of both criteria weights and performance measures then a best compromise should be conducted to recommend a method that answered their uncertainty concerns.

This paper applied AHP and PROMETHEE II to Boeing strategic marketing decision, other MCDM methods could be applied and could provide different outcomes with higher stability. AHP and PROMETHEE II were selected because they could be used to rank a set of alternatives and software to apply these methods were available. Moreover, the authors possessed good experience in applying these methods to strategic decisions (Haddad \& Sanders, 2018; Haddad \& Sanders, 2019; Haddad, Sanders \& Bausch, 2019; Haddad, Sanders \& Tewkesbury, 2019; Haddad et al, 2019).

PROMETHEE II was an outranking method based on outranking relations among alternatives, AHP was a method based on pairwise comparisons between alternatives. Other Multi Attribute Value Theory (MAVT) methods could be applied to this problem.

In the problem considered in this paper, both methods delivered the same outcome, different outcomes could be achieved if criteria weights or performance measures were altered. This paper did not compare the outcomes of different MCDM methods but considered the stability of the outcome of these methods. The authors applied different MCDM method to other problems (Haddad, 2017; Haddad \& Sanders, 2018; Haddad et al, 2019) The MCDM methods considered in these papers provided different outcomes when applied to the same problem. The authors analyzed the stability of other MCDM methods and recommended a method that delivered the most robust outcome. 
The stability of PROMETHEE II could be enhanced using indifference, preference and veto thresholds, these thresholds were not considered in this paper. Moreover, the Analytical Network Process (ANP) could be used instead of AHP to provide more stable results and consider interaction between criteria.

The problem considered in this paper could be simplified by restructuring it to consider five major evaluation elements (criteria), these criteria could consider all types of aircrafts. The five major criteria could be: Market size, Political factors enhancing the market size, Price competition, Product quality and Customer knowledge.

The large number of existing MCDM methods confuses potential decision makers, resulting in inappropriate pairing of methods and problems. The authors were not suggesting that one MCDM method was better than another, but that one MCDM method could deliver a more robust outcome than another for a specific problem. To recommend a single method for a problem, risk and uncertainty factors needed to be considered. Both performance measures and criteria weights were studied, and sensitivity analysis applied to performance measures and criteria weights to give a recommendation.

This paper presented a new framework and methods to recommend a MCDM method that delivered the most robust output from a variety of existing MCDM methods. AHP and PROMETHEE II were applied to BOEING strategic decisions, both methods provided the same outcome and showed that the most attractive market region was Asia followed by the United States. Both methods showed that the most critical criterion for this strategic decision was the Market Growth rate for 115 - 150 passengers planes, decision makers were encouraged to be accurate and give extra attention when providing judgment for this criterion since changes in its value might alter the outcome of the methods and shift the market attractiveness from Asia to the United States. Considering the scores of each market region with respect to criteria, AHP revealed that the Middle East market region showed high sensitivity towards the quality of all types of the planes. PROMETHEE II revealed that Asia and the United States were highly competitive, both market regions were highly sensitivity towards the quality of all types of the planes, a $1 \%$ change in the quality of any type of planes might shift the market attractiveness from Asia to the United States.

\section{Future Work}

Future work will consider applying ANP instead of AHP in an attempt to improve the decision making process and overcome some of the shortcomings of AHP regarding correlation ship between criteria.

This paper considered "Market size, Market growth rate, Market share, Political factors enhancing market size, Price competition, Product quality and Customer knowledge" as assessment criteria, future work will apply MCDM methods to other problems that considered the essential 4Ps (Product, Price, Place and Promotion) elements as analytical criteria. Moreover future work will consider the STP (Segmenting, Targeting and Positing mode) model for ranking the four global market regions.

Perfect consistency in real life problems is often hard to achieve. To investigate this, the authors intend to 
apply the new MCDM methods selection framework to other airline decisions with inconsistent pairwise

comparisons in various uncertain, fuzzy and risky environments.

\section{References:}

Al-Shabeeb, A. R. (2015), "A Modified Analytical Hierarchy Process Method to Select Sites For Groundwater Recharge in Jordan", PhD Dissertation, University of Leicester, U.K.

Arjomandia, A., Dakpob, K. and Seufert, J. (2018), "Have Asian airlines caught up with European Airlines? A byproduction efficiency analysis", transportation Research Part A, 116, pp. 389-403. doi.org/10.1016/j.tra.2018.06.031.

Ballestero, E. and Romero, C. (1998), "Multiple criteria decision making and its applications to economic problems", Netherlands, Kluwer Academic Publishers.

Barbosa, S., Ferreira, M. Nickel, E., Cruz, J., Forcellini, F. and Garcia, J. (2017), "Multi-criteria analysis model to evaluate transport systems: An application in Florianópolis", Brazil, Transportation Research Part A, 96, pp. 1 - 13. doi.org/10.1016/j.tra.2016.11.019.

Barnhart, C., Belobaba, P. and Odoni, A. (2003), "Applications of Operations Research in the Air Transport Industry", Transportation Science, 37(4), pp.368-391.

Brans, J. P. (1982), "Lingenierie de la decision. Elaboration sinstruments daide a la decision. Methode PROMETHEE", Nadeau R. Landry, M. (Eds), Laide a la Decisiobn: Nature, Instruments et Prespectives Davenir. Presses de Universite Laval, Quebec, Canada. pp. 183-214.

Collaborative Forum of Air Transport Stakeholders, (2003), "Fast Facts. Flyer obtainable from Forum Members", (International Air Transportation Association, www.iata.org).

Comes, T. Hiete, H., Wijngaards, N. and Schultmann, F., (2010), "Enhancing Robustness in MultiCriteria Decision-Making: A Scenario-Based Approach", 2010 International Conference on Intelligent Networking and Collaborative Systems.

Comes, T., Hiete, M. and Schultmann, F. (2013), "An Approach to Multi-Criteria Decision Problems Under Severe Uncertainty", J. Multi-Crit. Decis. Anal. 20, pp. 29-48. DOI: 10.1002/mcda.1487.

Durbach, I. and Stewart, T. (2011), "An experimental study of the effect of uncertainty representation on decision making", EJOR, 214, pp. 380-392.

Durbach, I. and Stewart, T. (2012), "Modeling uncertainty in multi-criteria decision analysis", EJOR, 223, pp. 114.

Eldarandaly, K., Ahmed, A. and AbdelAziz, N. (2009), "An Expert System for Choosing the Suitable MCDM Method for Solving a Spatial Decision Problem", Proceedings of the 9th Int. Conf. on Production Engineering, Design and Control, Alexandria, Egypt.

Expert Choice, (2013), Expert Choice Desktop. [online] Available at: http://www.expertchoice.com . [Accessed 3 January 2018].

Eyvindson, K., Öhman, K. and Nordström, E.-M. (2018), "Using uncertain preferential information from stakeholders to assess the acceptability of alternative forest management plans", J. Multi-Crit. Decis. Anal. 25, pp.43-52.

French, S. (2003), "Modelling making inferences and making decision: The roles of sensitivity analysis", Sociedadde Estadísticae Investigación Operativa (TOP), 11, pp. 229-251.

Grechuk, B. and Zabarankin, M. (2018), "Direct data-based decision making under uncertainty", EJOR, 267, pp. 200-211.

Guitouni, A. and Martel, J. M. (1997), "Tentative guidelines to help choosing an appropriate MCDM method", EJOR, 109, pp. 501-521.

Groves, D.G. and Lempert, R.J. (2007), "A new analytic method for finding policy-relevant scenarios", Global Environmental Change, 17(1), pp. 73-85.

Haddad, M. (2017), "A Framework That Uses Sensitivity Analysis to Select Multi Criteria Decision Making Methods", Journal of computing in systems and engineering, 18, pp. 413-419.

Haddad, M. and Sanders, D. (2018), "Selection of Discrete Multiple Criteria Decision Making Methods in the Presence of Risk and Uncertainty", Operations Research Perspectives, 5, pp. 357- 370.

Haddad, M. and Sanders, D., (2019), Selecting a best compromise direction for a powered wheelchair using PROMETHEE. IEEE Transactions on Neural Systems and Rehabilitation Engineering, 27(2), pp. 228-235. 
Haddad, M., Sanders, D. and Tewkesbury, G.E., (2019), "Selecting a Discrete Multiple Criteria Decision Making Method to decide on a Corporate Relocation". Archives of Business Research. 7(5), pp. $48-67$.

Haddad, M., Sanders, D. and Bausch, N. (2019), "Selecting a Robust Decision Making Method to Evaluate Employee Performance", International Journal of Management and Decision Making, Accepted and In Press.

Haddad, M., Sanders, D., Bausch, N., Tewkesbury, G., Gegov, A., Hassan, M., (2019), "Learning to Make Intelligent Decisions Using an Expert System for the Intelligent Selection of Either PROMETHEE II or the Analytical Hierarchy Process", In Advances in Intelligent Systems and Computing, 868, (pp. 1303 -1316). Springer.

Ishizaka, A. and Labib, A. (2009), "Analytic Hierarchy Process and Expert Choice: Benefits and Limitations", ORInsight, 22(4), pp. 201-220.

Ishizaka, A. and Siraj, S. (2018), "Are multi-criteria decision-making tools useful? An experimental comparative study of three methods", EJOR, 264, pp. 462-471.

Kornyshova, E. and Salinesi, C. (2007), "MCDM Techniques Selection Approaches: State of the Art", Proceedings of the 2007 IEEE Symposium on Computational Intelligence in Multicriteria Decision Making (MCDM 2007).

Laaribi, A. (2000), "SIG et analyse multicitere", Paris, France, Hermes Science Publication.

MacCrimmon, K. (1973), "An Overview of the multiple objective decision making in Multiple Criteria Decision Making", Columbia, The University of South Carolina Press.

Mahtani, U. and Garg, C. (2018), "An analysis of key factors of financial distress in airline companies in India using fuzzy AHP framework", Transportation Research Part A, 117, pp. 87-102. doi.org/10.1016/j.tra.2018.08.016.

Maleki, H. and Zahir, (2013), "S. A Comprehensive Literature Review of the Rank Reversal Phenomenon in the Analytic Hierarchy Process", J. Multi-Crit. Decis. Anal. 20, pp. 141-155.

Miller, G. (1956), "The magical number seven, plus or minus two: Some limits on our capacity for processing information.", Psychological Review, 21, 81-97.

Montibeller, G. and Franco, A. (2010), 'Multi-Criteria Decision Analysis for Strategic Decision Making' in Zopounidis, C. and Pardalos, P.M. eds., 2010. Handbook of multicriteria analysis (Vol. 103). Springer Science \& Business Media.

Mota, P. (2013), "Comparative Analysis of Multicriteria Decision Making Methods", Ph.D. dissertation, Elec. and Comp. Eng. Uni. Nova De Lisboa, Lisbon, Porugal.

Nassereddine, M. and Eskandarib, H. (2017), "An integrated MCDM approach to evaluate public transportation systems in Tehran", Transportation Research Part A, 106, pp. 427-439. doi.org/10.1016/j.tra.2017.10.013.

Norese, M. F., (2016), "A model-based process to improve robustness in Multicriteria Decision Aiding Interventions", J. Multi-Crit. Decis. Anal. 23, pp. 183-196. DOI 10.1002/mcda.1597

Olson, D., Mechitov, A. and Moshkovich, H. (2007), "Learning aspects of decision aids", Proceedings of the 15th Int. Conf. on MCDM'O0, IEEE Symposium on Computational Intelligence in Multicriteria Decision Making (MCDM 2007), Ankara, Turkey.

Omakarpasad S. and Kumar, S. (2006), "Analytical hierarchy process: An overview of applications", EJOR, 169, pp. 1-29.

Ozernoy, V. (1992), "Choosing the Best Multiple Criteria Decision Making Method", INFOR, 30(2), pp. 159 171.

Pacheco, R. and Fernandes, E. (2017), "International air passenger traffic, trade openness and exchange rate in Brazil: A Granger causality test", Transportation Research Part A, 101, pp. 22-29. doi.org/10.1016/j.tra.2017.04.026.

Project Management Institute. (2004), "Risk Management Plan in A guide to the project management body of knowledge (PMBOK)", 6th ed. Newtown Square, Pa, USA.

Razmak, J. and Aouni, B. (2015), "Decision Support System and Multi-Criteria Decision Aid: A State of the Art and Perspectives, J. Multi-Crit. Decis. Anal. 22, pp. 101-117.

Roy, B. (1985), Methodologie multicitere a la Decision: Methodes et Cas, Economica.

Roy B. and Slowinski, R. (2013), "Questions guiding the choice of a multicriteria decision aiding method", Euro J. Decis. Process, 1, pp. 69-97. 
Roy, B. (2010), 'To Better Respond to the Robustness Concern in Decision Aiding: Four Proposals Based on a Twofold Observation' in Zopounidis, C. and Pardalos, P.M. eds., 2010. Handbook of multicriteria analysis (Vol. 103). Springer Science \& Business Media.

Saaty R. W. (1987), "THE ANALYTIC HIERARCHY PROCESS-WHAT IT IS AND HOW IT IS USED", Mat/d Modelling, 9(3-5), pp. 161-176.

Saaty T. L. (1994), "How to Make a Decision: The Analytic Hierarchy Process", INTERFACES, 24 (6) pp. 19- 43.

Saaty, T. L. (2004), "Decision Making - The Analytical Hierarchy and Network Processes (AHP/ANP)", Journal of Systems Science and Systems Engineering, 13 (1), pp. 1- 35.

Saaty, T. (2008), "Decision making with the analytic hierarchy process", Int. J. Services Sciences, 1 (1).

Saaty, T. (2012), "Models, Methods, Concepts and Applications of the Analytic Hierarchy Process", International Series in Operations Research and Management Science. 2nd ed. 2012 Edition. Springer.

Saaty, T. and Ergu, D. (2015), "When is a Decision Making Method Trustworthy? Criteria for Evaluating MultiCriteria Decision Making Methods", International Journal of Information Technology \& Decision Making, 14(6), pp. 1171-1187. DOI: 10.1141/S021962201550025X.

Saltelli, A., Tarantola, S. and Campolongo, F. (2000), "Sensitivity Analysis as an Ingredient of Modelling", Statistical Science, 15(4), pp. $377-395$.

Scholten, L., Schuwirth, N., Reichert, P. and Lienert, J. (2015), "Tackling uncertainty in multi-criteria decision analysis-An application to water supply infrastructure planning", EJOR, 242, pp. 243-260.

Sha, Z., Moolchandani, K., Panchal, J. H., Delaurentis, D. A. (2015), "Modeling Airlines Decisions On Route Selection Using Discrete Choice Models - Data and Supplementary Materials", Purdue University Research Repository. doi:10.4231/R74747TG

Simon HA. (1979), "Rational decision making in business organizations", The American Economic Review, 69 (4), pp. 493-513.

Stewart, T. (2005). Dealing with uncertainties in MCDA (multi-criteria decision analysis), InJ. Figueira, S.Greco, and M.Ehrgott (Eds.), Multiple criteria decision analysis State of the art annotated surveys, 78, 445470. New York: Springer.

Sun, X., Gollnick, V. and Stumpf, E. (2011), "Robustness Consideration in Multi-Criteria Decision Making to an Aircraft Selection Problem", J. Multi-Crit. Decis. Anal. 18, pp. 55-64.

Tscheikner-Gratl, F., Egger,P., Rauch, W. and Kleidorfer, M. (2017), "Comparison of Multi-Criteria Decision Support Methods for Integrated Rehabilitation Prioritization", Water, 9(68), pp. 2 -68.

Ulengin, F., Topcu, Y. and Sahin, S. (2007), "An artificial neural network approach to multicriteria method Selection", Proceedings of the 15th Int. Conf. on MCDM'00, IEEE Symposium on Computational Intelligence in Multicriteria Decision Making (MCDM 2007), Ankara, Turkey, 2007.

Vanderpas, J., Walker, W., Marchau, V., Vanwee G. and Agusdinata, D. (2010), "Exploratory MCDA for Handling Deep Uncertainties: The Case of Intelligent Speed Adaptation Implementation J. Multi-Crit. Decis. Anal. 17, pp. 1-23. DOI: $10.1002 /$ mcda. 450

Vincke, P. (1999), "Robust Solutions and Methods in Decision-Aid. Journal of Multi-Criteria", Decision Analysis, 8, pp. 181-187.

Vincke, P. (1995), "A short note on a methodology for choosing a decision-aid method, Advances in Multicriteria Analysis", P. M. Pardalos, Y. Siskos and C. Zopoundis (Eds.), Kluwer Academic Publishers (pp. 3-76). Netherlands.

Wang. J.J., Jing, Y.Y. and Zhang, C.F. (2010), "Review on multicriteria decision analysis aid in sustainable energy decision-making", Renewable and Sustainable Energy Reviews, 13, pp. 2263-2278.

Wolters, W. and Mareschal, B. (1995), "Novel types of sensitivity analysis for additive MCDM methods", EJOR, 81, pp. $281-290$.

Xiaohann, Y., Zeshui, X. and Ying, M. (2013), "Prioritized Multi-Criteria Decision Making Based on the Idea of PROMETHEE", Procedia Computer Science, 17 pp. $449-456$.

Yu, X., Xu, Z., Hu, J. and Liu, S. (2017), "Systematic Decision Making: AN Extended Multi-Criteria Decision Making Model", Technological and Economic Development Of Economy, 23(1), pp. 157-177. DOI: 10.3846/20294913.2016.1212121.

Zeleny, M. (2011), “Multiple Criteria Decision Making (MCDM): From Paradigm Lost to Paradigm Regained?”, J. Multi-Crit. Decis. Anal. 18, pp. 77-89. 